\title{
Management of Diabetic Macular Edema
}

John D. Pitcher and Jean-Pierre Hubschman*

Retina Division, Jules Stein Eye Institute, David Geffen School of Medicine at University of California, Los Angeles, California 90095-7000, USA

Keywords: Diabetes; Macular edema; Anti-VEGF; Photocoagulation

\section{Introduction}

Diabetic macular edema (DME) is a common cause of vision loss and decreased vision-related quality of life (VRQoL) in workingaged Americans $[1,2]$. Both vision and VRQoL may be modified by treatment [3], and recent therapeutic advancements have provided the flexibility to customize management for the patient's individual needs. Pharmacotherapy, photocoagulation, and vitreoretinal surgery are tools that can be used to create a treatment algorithm for diabetic macular edema.

\section{Metabolic Control}

Optimizing systemic factors that may contribute to ongoing damage to the retinal vasculature is essential to successful outcomes in managing DME. The Diabetes Control and Complications Trial (DCCT) demonstrated that intensive glycemic control provides a hazard reduction in retinopathy progression of $79 \%$ at four years and $53 \%$ at ten years [4]. Data from the Early Treatment Diabetic Retinopathy Study (ETDRS) suggested that lipid lowering may decrease hard exudate formation in the macula and associated visual loss, as well as decreasing the overall risk of cardiovascular mortality [5]. Recent population-based cross sectional studies also identified a relationship between high serum total cholesterol and clinically significant macular edema (CSME) [6].

In the United Kingdom Prospective Diabetes Study Group (UKPDS), patients with strict blood pressure control $(10 \mathrm{mmHg}$ lower systolic pressure) experienced 34\% reduction in worsening retinopathy [7]. Glitazones oral hypoglycemic agents have been implicated as a cause of macular edema, and cessation may result in rapid improvement in visual acuity [8]. Each office visit represents an opportunity to counsel the patient and coordinate care to help decrease retinal vascular complications through improved metabolic control.

\section{Evaluation of DME}

Randomized trials have contributed greatly to our understanding of how to manage DME. In most studies, patients with different phenotypes are combined to achieve large enough groups to achieve statistically significant results. Identifying the underlying pathophysiologic mechanism is critical to successful therapeutic intervention. Vascular permeability, inflammation, traction, ischemia, and neuronal changes may all contribute to vision loss. At the initial examination, high magnification or contact lens biomicroscopy, fluorescein angiography (FA), and spectral-domain optical coherence tomography (SD-OCT) should be utilized to subclassify DME to guide treatment (Figure 1).

\section{Focal macular photocoagulation}

For over two decades, focal macular laser (FML) photocoagulation has been the standard of care for DME. The ETDRS found a 50\% reduction in the likelihood of severe vision loss with grid-style FML [9]. The Diabetic Retinopathy Clinical Research Network (DRCR.net) study group more recently reported a ten-letter gain in nearly onethird of patients treated with laser. Nevertheless, 19\% still experienced progressive visual loss [10].

DME often occurs in association with a circinate ring of hard exudates surrounding microaneurysms (Figure 2). This subtype is focal diabetic macular edema (FDME), and a localized vascular abnormality is the primary pathologic feature. If vision threatening, focal macular photocoagulation monotherapy, titrated to achieve a color change in the targeted leaking aneurysms, can still be considered as a viable treatment option.

\section{Intravitreal anti-vascular endothelial growth factor therapy}

Diffuse diabetic macular edema (DDME) is a different disease process that usually proves more difficult to manage. Breakdown of the blood-retinal barrier may lead to cystoid macular edema (CME) and even serous macular detachment (Figure 3). Recent studies have suggested that vascular endothelial growth factor (VEGF) mediates vascular permeability in diabetic eyes [11,12]. Furthermore, levels of VEGF and other vasoactive molecules correlate strongly with the presence of DME [13]. Based on this evidence, pharmacotherapy has been used to specifically target the pathophysiologic mechanisms underlying DME.

In 2010, the Ranibizumab for Edema of the mAcula in Diabetes (READ-2) study reported equivalent visual outcomes of intravitreal anti-VEGF therapy to FML at two years, and gains were experienced at as early as six months by the injection group. Supplementing with FML (combination therapy) halved the number of needed injections [14]. More recently, the RESTORE study demonstrated greater improvement in best-corrected visual acuity (BCVA) at one year with ranibizumab with or without laser compared with laser monotherapy [15]. In contrast to READ-2, anatomic and VRQoL outcomes were superior in the anti-VEGF groups. The number of total injections over the year for the injection only group was 7.1 compared with 4.8 in the combination therapy group. No cases of endophthalmitis occurred and there was no increased risk of cardiovascular or cerebrovascular events in the 345 patients who received multiple injections over the one-year study.

In addition, the randomized, sham-controlled, 36 month phase III trials of ranibizumab for DME (RIDE and RISE) both met their primary

*Corresponding author: Jean-Pierre Hubschman, MD, Associate Professor of Clinical Ophthalmology, Jules Stein Eye Institute, 100 Stein Plaza, Los Angeles, CA 90095-7000, USA, Tel: (310) 206-5004; Fax: (310) 794-7905; E-mail: hubschman@ jsei.ucla.edu

Received November 12, 2011; Accepted December 17, 2011; Published December 21, 2011

Citation: Pitcher JD, Hubschman JP (2011) Management of Diabetic Macula Edema. J Diabetes Metab S3:002. doi:10.4172/2155-6156.S3-002

Copyright: @ 2011 Pitcher JD, et al. This is an open-access article distributed under the terms of the Creative Commons Attribution License, which permits unrestricted use, distribution, and reproduction in any medium, provided the original author and source are credited. 


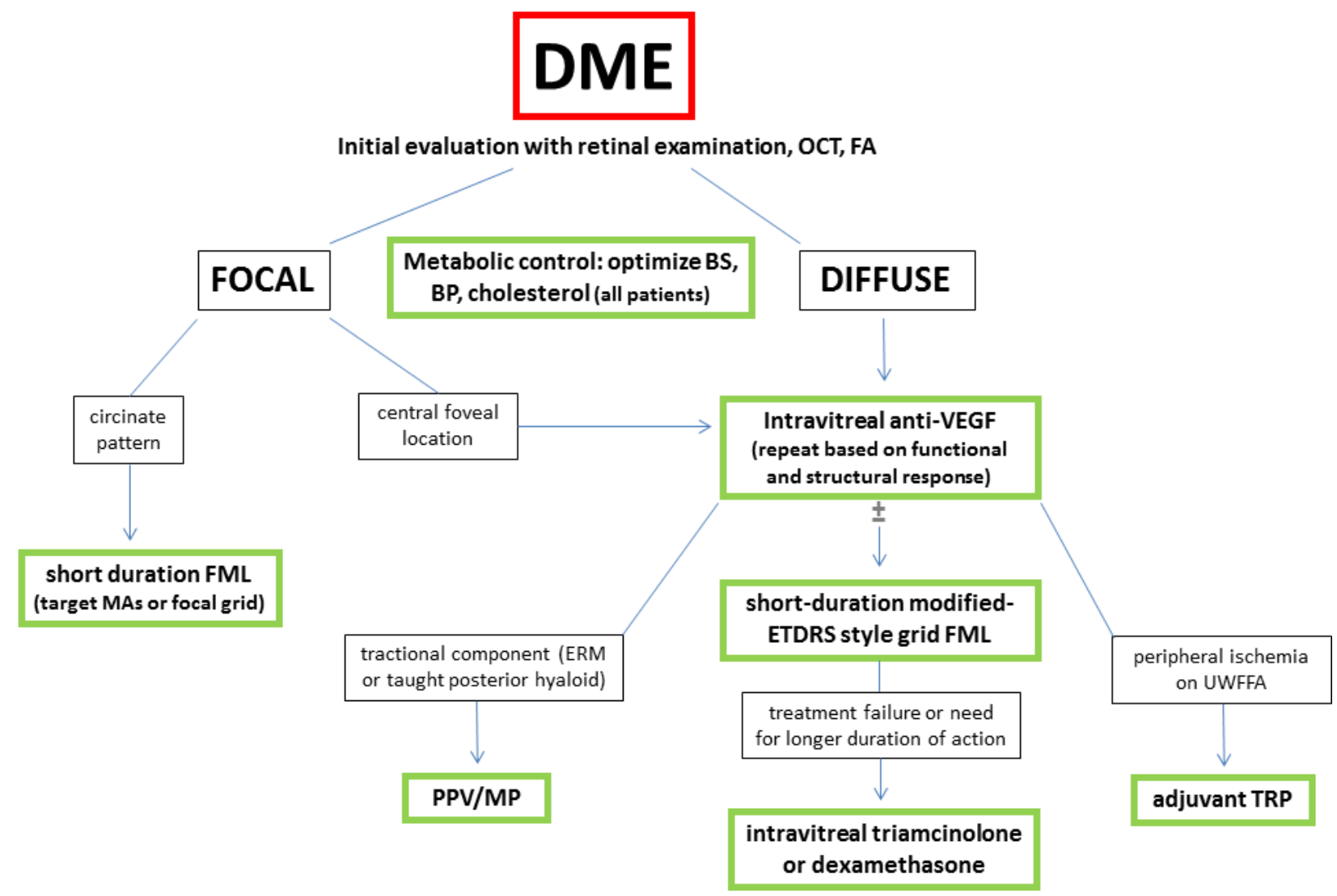

Figure 1: A treatment algorithm for diabetic macular edema (DME).

endpoints (15 ETDRS letter gain from baseline), suggesting that antiVEGF therapy is effective in improving vision compared with placebo. DA VINCI, a phase 2 study of aflibercept (formerly VEGF Trap) for DME with permitted laser rescue, also showed promising visual gains at one year follow up [16].

Although intravitreal steroids have additional anti-inflammatory properties along with targeting VEGF, the clinical benefits have been less impressive. Because they accelerate cataract and raise intraocular

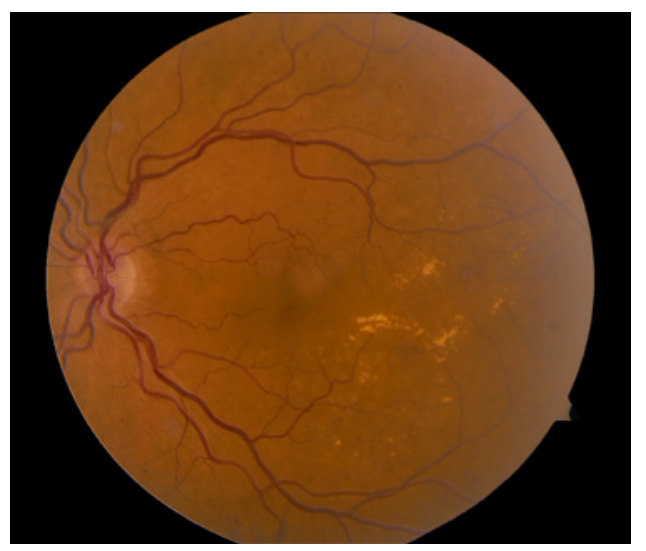

Figure 2: Circinate hard exudates around a cluster of microaneurysms in the macula of a diabetic patient.

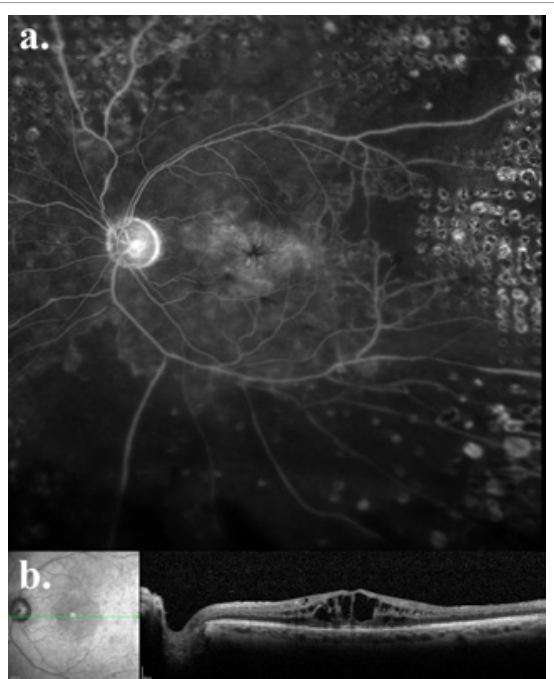

Figure 3: Diffuse diabetic macular edema (DDME); macular view during the late phase of an ultra-wide field fluorescein angiogram (a) and SD-OCT (b).

pressure, they may be an appropriate option \pm FML in non-responders who are pseudophakic or those who have had successful filtration surgery to control glaucoma (DRCR.net protocol I, phase 3 FAME trial, phase 3 PLACID trial) [17-19].

Though no drugs are FDA approved for DME, bevacizumab may 
be the initial choice to maximize patient access (minimizing expense) and practitioner convenience. No definitive dosing guidelines exist for pharmacotherapy. Close follow-up with monthly re-evaluation helps determine functional (visual acuity) and structural (SD-OCT) response as well as the patient's own subjective assessment. The DRCR.net investigators found evidence that prompt or deferred laser following intravitreal anti-VEGF injection results in greater visual acuity gains over controls [17]. To help reduce the burden of monthly injections in cases with multiple areas of leakage on FA, a modified ETDRS-style macular grid photocoagulation can be performed within two weeks after an anti-VEGF treatment. Parameters vary according to the status of each patient's media and fundus pigmentation, and are titrated to obtain a minimally visible burn. Shorter duration settings than those used in DRCR.net cohorts have similar visual outcomes with the benefit of higher spatial localization of the lesion with less expansion over time [20].

\section{Peripheral targeted retinal photocoagulation}

The peripheral angiographic features of retinal vascular disease and their association with vision-threatening complications can be evaluated using ultra wide-field fluorescein angiography (UWFFA). A high level of untreated nonperfusion, i.e. an elevated "ischemic index," is correlated with macular edema in retinal vein occlusions, presumably through a VEGF-mediated mechanism [21]. Similar trends exist in DME [22]. In animal models of diabetic retinopathy, the inner retinal oxygen levels increase by as much as $50 \%$ following photocoagulation, which may decrease the stimulus for VEGF production [23]. Laser may also act by direct destruction of the cells responsible for producing proaniogenic cytokines [24]. UWFFA is a tool that may therefore be used to guide treatment of those with increased ischemic indices via "targeted" retinal photocoagulation (TRP; Figure 4).

\section{Vitreoretinal surgery}

DME may decrease after spontaneous posterior vitreous detachment (PVD) [25] or surgical removal of the vitreous. These observations have led to studies of the efficacy of pars plana vitrectomy (PPV) for DME. The DRCR.net investigators organized a prospective cohort of 87 eyes with vision worse than 20/63 due to DME with evidence of vitreomacular traction [26]. Median central foveal thickness on OCT decreased by $160 \mu \mathrm{m}$, with at least a $50 \%$ reduction in $68 \%$ of patients. Factors associated with better outcome included worse

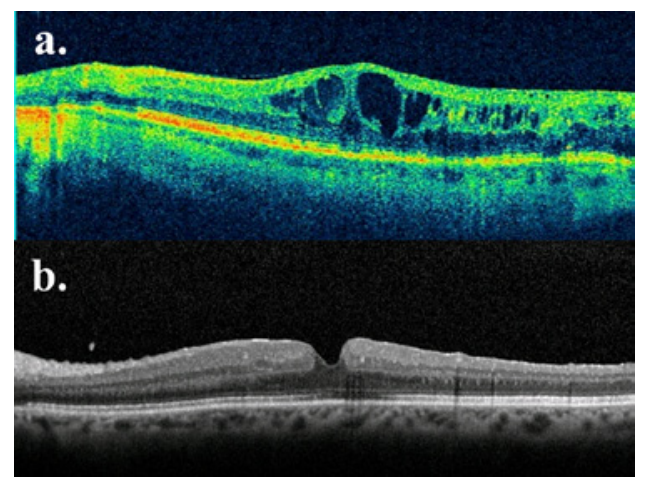

Figure 4: SD-OCT of a patient with $20 / 80$ vision and DME exacerbated by an epiretinal membrane who failed multiple intravitreal anti-VEGF treatments (a). Two months after PPV with detachment of the posterior hyaloid, ERM/ ILM peeling, and bevacizumab injection his vision improved to 20/40 with restoration of a more normal appearing fovea (b).

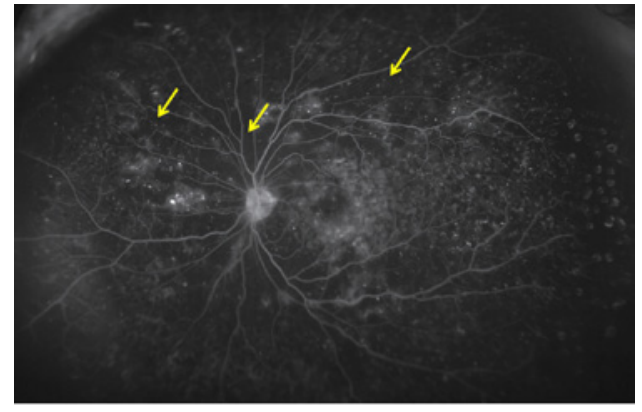

Figure 5: Ultra wide-field fluorescein angiography of a patient with DME and areas of untreated mid-peripheral non-perfusion (arrows).

visual acuity and retinal thickening at baseline, epiretinal membrane (ERM) and internal limiting membrane (ILM) removal during surgery, and pre-operative evidence of vitreoretinal abnormalities on OCT. Based on this data, patients who have these characteristics (Figure 5) may be offered PPV with ERM and ILM peeling, usually after failure of pharmacotherapy. It should be noted that subsequent intravitreal injections in the post-vitrectomized eye will be under augmented pharmacokinetics, with faster clearance of the drug. Extended release devices may overcome this obstacle. CHAMPLAIN, an open label phase $3 \mathrm{~b}$ trial of the dexamethasone implant for DME in vitrectomized eyes, showed that nearly one-third of patients experienced a two line improvement in visual acuity at week 13 [27]. In the DRCR.net study, cataract progression, a common risk of vitrectomy, was noted at 6 months following vitrectomy in $38 \%$ of patients who had initially clear lenses [26].

\section{Conclusion}

DME can be a difficult but rewarding entity to treat. It requires thoughtful consideration of the anatomic features through careful examination aided by retinal imaging techniques. Systemic and social factors may even play a role (e.g. using intravitreal steroids in a patient with recent thromboembolic events or inability to follow-up for the more frequent dosing of other anti-VEGF agents). No patients present identically, and combining pharmacotherapy, macular and peripheral targeted photocoagulation, and surgical techniques is often necessary to achieve good outcomes and satisfied patients.

\section{References}

1. Klein R, Klein BE, Moss SE, Cruickshanks KJ (1998) The Wisconsin Epidemiologic Study of Diabetic Retinopathy: XVIII. The 14-year incidence and progression of diabetic retinopathy and associated risk factors in type 1 diabetes. Ophthalmology 105: 1801-1815.

2. Hariprasad SM, Mieler WF, Grassi M, Green JL, Jager RD, et al. (2008) Visionrelated quality of life in patients with diabetic macular oedema. $\mathrm{Br} \mathrm{J}$ Ophthalmol 92: 89-92.

3. Tranos PG, Topouzis F, Stangos NT, Dimitrakos S, Economidis P, et al. (2004) Effect of laser photocoagulation treatment for diabetic macular oedema on patient's vision-related quality of life. Curr Eye Res 29: 41-49.

4. White NH, Sun W, Cleary PA, Danis RP, Davis MD, et al. (2008) Prolonged effect of intensive therapy on the risk of retinopathy complications in patients with type 1 diabetes: 10 years after the Diabetes Control and Complications Trial. Arch Ophthalmol 126: 1707-1715.

5. Chew EY, Klein ML, Ferris FL, Remaley NA, Murphy RP, et al. (1996) Association of elevated serum lipid levels with retinal hard exudate in diabetic retinopathy. Early Treatment Diabetic Retinopathy Study (ETDRS) Report 22 Arch Ophthalmol 114: 1079-1084. 
6. Raman R, Rani PK, Kulothungan V, Rachepalle SR, Kumaramanickavel G, et al. (2010) Influence of serum lipids on clinically significant versus nonclinically significant macular edema: SN-DREAMS Report number 13. Ophthalmology 117: 766-772.

7. (1998) Tight blood pressure control and risk of macrovascular and microvascular complications in type 2 diabetes: UKPDS 38. UK Prospective Diabetes Study Group. BMJ 317: 703-713.

8. Ryan EH, Han DP, Ramsay RC, Cantrill HL, Bennett SR, et al. (2006) Diabetic macular edema associated with glitazone use. Retina 26: 562-570.

9. (1985) Photocoagulation for diabetic macular edema. Early Treatment Diabetic Retinopathy Study report number 1 . Early Treatment Diabetic Retinopathy Study research group. Arch Ophthalmol 103: 1796-1806.

10. Aiello LP, Edwards AR, Beck RW, Bressler NM, Davis MD, et al. (2010) Factors associated with improvement and worsening of visual acuity 2 years after focal/ grid photocoagulation for diabetic macular edema. Ophthalmology 117: 946953.

11. Antcliff RJ, Marshall J (1999) The pathogenesis of edema in diabetic maculopathy. Semin Ophthalmol 14: 223-232.

12. Funatsu H, Yamashita H, Nakamura S, Mimura T, Eguchi S, et al. (2006) Vitreous levels of pigment epithelium-derived factor and vascular endothelial growth factor are related to diabetic macular edema. Ophthalmology 113: 294301.

13. Funatsu H, Noma H, Mimura T, Eguchi S, Hori S (2009) Association of vitreous inflammatory factors with diabetic macular edema. Ophthalmology 116: 73-79.

14. Nguyen QD, Shah SM, Khwaja AA, Channa R, Hatef E, et al. (2010) Two-year outcomes of ranibizumab for edema of the macula in diabetes (READ-2) study. Ophthalmology 17: 2146-2151.

15. Mitchell P, Bandello F, Schmidt-Erfurth U, Lang GE, Massin P, et al. (2011) The RESTORE study: Ranibizumab monotherapy or combined with laser versus laser monotherapy for diabetic macular edema. Ophthalmology 118: 615-625.

16. Do DV. Anti-VEGF therapy for DME: The DaVinci Study. Paper presented at: Angiogenesis, exudation and degeneration 2011; Feb 12, 2011; Miami, FL.

17. Elman MJ, Bressler NM, Qin H, Beck RW, Ferris FL, et al. (2011) Expanded 2-year follow-up of ranibizumab plus prompt or deferred laser or triamcinolone plus prompt laser for diabetic macular edema. Ophthalmology 118: 609-614

18. Pearson PA, Comstock TL, Ip M, Callanan D, Morse LS, et al. (2011) Fluocinolone acetonide intravitreal implant for diabetic macular edema: a 3 -year multicenter, randomized, controlled clinical trial. Ophthalmology 118 : 1580-1587.

19. Safety and efficacy of a new treatment in combination with laser for diabetic macular edema.

20. Jain A, Collen J, Kaines A, Hubschman JP, Schwartz S (2010) Short-Duration focal pattern grid macular photocoagulation for diabetic macular edema: fourmonth outcomes. Retina 30: 1622-1626.

21. Prasad PS, Oliver SC, Coffee RE, Hubschman JP, Schwartz SD (2010) Ultra wide-field angiographic characteristics of branch retinal and hemicentral retinal vein occlusion. Ophthalmology 117: 780-784.

22. Oliver SC, Schwartz SD (2010) Peripheral vessel leakage (PVL): A new angiographic finding in diabetic retinopathy identified with ultra wide-field fluorescein angiography. Semin Ophthalmol 25: 27-33

23. Budzynski E, Smith JH, Bryar P, Birol G, Linsenmeier RA (2008) Effects of photocoagulation on intraretinal P02 in cat. Invest Ophthalmol Vis Sci 49: 380-389.

24. Ogata N, Ando A, Uyama M, Matsumura M (2001) Expression of cytokines and transcription factors in photocoagulated human retinal pigment epithelium cells. Graefes Arch Clin Exp Ophthalmol 239: 87-95.

25. Hikichi T, Fujio N, Akiba J, Azuma Y, Takahashi M, et al. (1997) Association between the short-term natural history of diabetic macular edema and the vitreomacular relationship in type II diabetes mellitus. Ophthalmology 104: 473478.

26. Flaxel CJ, Edwards AR, Aiello LP, Arrigg PG, Beck RW, et al. (2010) Factors associated with visual acuity outcomes after vitrectomy for diabetic macular edema: diabetic retinopathy clinical research network. Retina 30: 1488-1495.

27. Boyer DS, Faber D, Gupta S, Patel SS, Tabandeh H, et al. (2011) Dexamethasone intravitreal implant for treatment of diabetic macular edema in vitrectomized patients. Retina 31: 915-923.
This article was originally published in a special issue, Diabetic Retinopathy handled by Editor(s). Dr. Caroline J Magri, Mater Dei Hospital, Malta 